\title{
O EXAURIMENTO DO ESTADO EM FACE DA SOCIAL DEMOCRACIA
}

\author{
THE EXHAUSTION OF THE STATE IN REASON OF SOCIAL DEMOCRACY
}

\author{
${ }^{1}$ Eduardo Felipe Veronese
}

\section{Resumo}

O modelo econômico adotado pelo país é a base para compreender o seu desenvolvimento. No Brasil, optou-se pelo modelo econômico liberal, face às suas características, como a tripartição de poderes, dialogando com o modelo econômico social. A partir desses conceitos, compreendem-se os objetivos referentes ao padrão democrático implementado. Apesar dos anseios do Estado Democrático de Direito possuírem elevada relevância, pois defendem os ideias liberais e a efetivação dos direitos fundamentais e sociais, na prática o sistema implementado tem sofrido distorções, afastando os princípios estabelecidos da realidade, deixando o modelo econômico em vias de se exaurir.

Palavras-chave: Separação de Poderes; Padrão democrático; social democracia; Estado Democrático de Direito; falência do Estado.

\begin{abstract}
The economic model adopted by the country is the basis for understanding its development. In Brazil, we opted for the liberal economic model, based on its characteristics, such as the tripartite division of powers, in dialogue with the social economic model. From these concepts, understand it if the objectives for the democratic standard implemented. Despite the wishes of Law Democratic State possess highly relevant, as they defend the liberal ideas and the realization of fundamental and social rights, in practice the implemented system has been distorted, keeping the principles of reality, leaving the model economic in the process of exhausting.
\end{abstract}

Keywords: Separation of powers; democratic standard; social democracy; democratic state; state failure.

\footnotetext{
${ }^{1}$ Mestrando em Direito Empresarial e Cidadania na Faculdade de Direito do Centro Universitário Curitiba, Unicuritiba - PR, (Brasil). E-mail: eduardoveronese@ outlook.com
} 


\section{INTRODUÇÃO}

Durante todo o período histórico existiram diversos modelos econômicos sendo aplicados às mais diversas realidades sociais, sendo que, a partir de toda a experiência prática, prevaleceram os modelos liberal e social, que sofreram algumas adaptações ao passar do tempo, conforme a demanda social se apresentava na realidade.

Desses modelos econômicos, em especial do conceito inserido no Estado liberal, surgiram as teorias da separação de poderes. A partir das lições dos teóricos liberais, como Locke e Rousseau, foi insculpida a tripartição de poderes, resultando no estabelecimento do Poder Executivo, Poder Legislativo e Poder Judiciário, cada um com suas atribuições específicas, mas todos sendo responsáveis por efetivar os objetivos dentro do sistema de freios e contrapesos.

Por consequência, baseando-se nos modelos econômicos e no conceito da tripartição de poderes, definiu-se no Brasil o seu conceito de democracia, pautada não apenas no modelo econômico liberal e nem apenas no modelo econômico social, mas dialogando entre os dois padrões, objetivando proporcionar maior benefício a todas as classes sociais.

Atento a essas situações, objetiva-se aqui, apresentar inicialmente os modelos econômicos liberal e social, a fim de demonstrar o trajeto percorrido desde a formação desses conceitos até o adoção deles no sistema estabelecido pelo Brasil, especialmente em face das normas consagradas na Constituição da República Federativa do Brasil de 1988.

Em seguida, far-se-á um apanhado acerca da separação de poderes, entre Executivo, Legislativo e Judiciário, as razões para a sua existência e as consequências da aplicação desses conceitos para a definição do padrão democrático.

Por fim, pretende-se apresentar a realidade brasileira e as distorções que os sistemas adotados têm proporcionado, de modo a constatar a necessidade de modificações nas formas de pensar o Estado e nas políticas públicas a serem implementadas para a manutenção da Administração Pública.

\section{OS MODELOS ECONÔMICOS}

O modelo de Estado conforme se constata nos dias atuais é decorrente de uma série de fatores históricos. Antes dele, outras formas de comunidades organizadas já existiam. A Pólis (cidade-estado grega) existiu até o surgimento da Civita (romana), momento em que o poder 
era mantido em posse da Igreja. Porém, a burguesia foi responsável pela criação da abstração chamada Estado.

Em suma, com o surgimento da burguesia e seu fortalecimento a partir das produções geradas às margens dos palácios e trocas entre seus pares, o papa e os reis começaram a ser financiados por essa classe, por exemplo nas cruzadas, tendo em vista que a inexistência de produção por eles exauriu suas riquezas. Os abusos e a falência do absolutismo monárquico possibilitou a superação da incoerência existente até então entre a organização política e a demanda social. (RAMOS, 2015, p. 8)

Naquele momento, o poder estava materializado na figura de um homem. Percebendo isso, a burguesia criou uma entidade, chamada de Estado, consubstanciado numa abstração, algo que não se materializa. A burguesia institucionaliza o poder, de modo que o poder supostamente é de todos, impessoal, não aceitando que a igreja seja a detentora dele. Substituiuse o príncipe pelo princípio. Quem detém o poder econômico acaba por conquistar, também, o poder político.

Para a manutenção do poder nas mãos de uma minoria, burguesa, consagra-se o que se denominou contrato social, considerado uma espécie de regulamentação para o convívio em sociedade, de modo que cada indivíduo confere parte de sua liberdade ao ente denominado Estado para que ele seja capaz de gerir a vida dos indivíduos enquanto inseridos nesse contexto, transformando a liberdade em direitos.

Considerando esse momento proporcionado pelas transformações históricas, com a queda do feudalismo, o capitalismo ganhou força e se tornou o sistema preponderante, justificado a partir do modelo de liberalismo que se implantou, com a nova forma de organização política construída no monopólio do próprio Estado.

Três fenômenos foram os impulsionadores do liberalismo no século XVIII: a consolidação de um novo modelo econômico baseado na livre iniciativa (o capitalismo), o deslanchar do processo de Revolução Industrial e o nascimento da democracia política (uma nova forma de vivenciar a esfera pública) através da Revolução Americana. Assim, o liberalismo transformou a cosmovisão que o pressupunha em três grandes níveis: o econômico, o social e o político. De toda forma, esses fatos estão intrinsecamente ligados, e por isso pode-se afirmar que o liberalismo desenvolve-se com e para a expansão do capitalismo. (RAMOS, 2015, p. 95)

John Locke foi o criador do liberalismo inglês, da monarquia constitucional inglesa e do parlamentarismo inglês. Segundo ele, no Estado Originário o homem tem liberdade, o que faz com que esse estado seja instável, mesmo que exista a razão para orientá-la. O crime, no 
sentido político de ser qualquer conduta ofensiva ao direito, é que desestabiliza o Estado Originário. O surgimento de um crime origina a sensação de vingança, que, por consequência, originará um novo crime, causando a instabilidade.

Considerando as liberdades individuais, cada indivíduo renuncia o que permitia a punição privada, a liberdade de fazer justiça pelas próprias mãos, entregando parcela mínima ao Estado para punir o crime. O Estado nasce como Poder de Execução. Porém, faz-se necessário ter previsão do que é crime. Por essa razão, cabe ao Poder Legislativo a definição desses conceitos. A lei define que o Governo só pode invadir o espaço privado para aplicar a sanção penal quando a lei autorizar, visto que é ela quem define o que é crime. O indivíduo tem a liberdade de fazer tudo que a lei não proíbe. Portanto, o espaço de atuação do governo é muito pequeno. Trata-se da liberdade negativa, que se estende até encontrar uma proibição.

Tratando-se de seres humanos existe a dificuldade de se concretizar a imparcialidade, objetividade e neutralidade ao julgar as próprias causas em que tenham ocorrido transgressões, razão pela qual a sanção a ser aplicada eventualmente poderá não ser proporcional ao crime efetivamente cometido. Assim, faz-se necessário o estabelecimento de um juiz comum a todos, capaz de aplicar corretamente as normas positivadas, proporcionando um padrão de justiça. Por consequência, ocorreu o abandono do estado de natureza para dar lugar ao consentimento coletivo como fundamento do Estado. (VILELA, 2014, p. 5)

Porém, frente à existência de falhas na concepção liberal de economia, por exemplo para coibir abusos praticados por particulares na prática empresarial, o Estado se viu forçado a praticar atos intervencionistas, não só necessários como também legítimos, causando o declínio do liberalismo clássico. (TAVARES, 2011, p. 49)

\footnotetext{
Apesar das conquistas da sociedade civil, o liberalismo democrático não atingiu as expectativas em termos de emancipação humana, pois, tendo em vista o caráter excludente do sistema capitalista agravado pelas consequências da livre-concorrência, ou seja, a disputa desenfreada e a acumulação desigual do capital, provocaram um aprofundamento das desigualdades sociais. Como consequência, o foco político desloca-se para a implementação de algumas medidas de caráter popular, ou de bemestar-social, o que denominou o período do Estado de Bem-Estar Social. (ROSSIGNOLI; FERRER, 2014, p. 5)
}

O desenvolvimento cultural proporcionado com o passar dos anos, em todo o mundo, possibilitou que atualmente se utilize como fundamento para as políticas implementadas nos países os modelos econômicos social e liberal, sofrendo, cada um, as adaptações necessárias conforme a realidade específica de cada Estado que os utiliza. 
A relação que se estabelece entre o Direito e a economia teve maior relevância a partir da formação da sociedade industrial e do surgimento do capitalismo, que remete, basicamente, à Primeira Revolução Industrial ocorrida na Inglaterra, por volta de 1820 a 1840 e com a Segunda Revolução Industrial, nos anos de transição entre 1840 e 1870. (KOURY, 2014, p. 3)

(...) direito econômico assim perspectivado, afirma-se fundamentalmente como o direito público que tem por objetivo o estudo das relações entre os entes públicos e os sujeitos privados, na perspectiva da intervenção do Estado na vida econômica", sendo seu "objeto as regras jurídicas que disciplinam a intervenção do Estado na economia. (MONCADA, 1978, p. 15)

O desenvolvimento do Direito Econômico no Brasil se deu a partir do processo de industrialização ocorrido na década de 1930, baseando-se na ideologia desenvolvimentista como reação à crise vivida pelo capitalismo no período da década de 1920. Um dos principais expoentes desse momento foi Washington Albino Peluso de Souza, responsável pela compreensão do direito econômico como instrumento à política econômica para a transformação das estruturas existentes no país naquele período, a fim de promover o desenvolvimento nacional. (BERCOVICI, 2013, p. 261)

Segundo José Afonso da Silva, no Brasil, a Constituição Federal de 1988 optou pela adoção do sistema capitalista, tendo definido em seu artigo 170 que a ordem econômica encontra-se fundada na propriedade e na iniciativa privadas, seguindo os ditames desse modelo que é pautado pelas liberdades de iniciativa e de concorrência. (SILVA, 2003, p. 776)

Apesar disso, há que se analisar o duplo aspecto inserido no texto da Constituição Federal de 1988, pois se de um lado ressalta a livre concorrência, influenciada pelo cenário da estratégia global de modernização liberal da década de 1980, por outro lado apresenta preocupação e assegura a necessidade de redução das desigualdades regionais e sociais, principalmente por meio dos artigos referentes aos direitos e garantias fundamentais. (ROSSIGNOLI; FERRER, 2014, p. 12)

Portanto, constata-se que o Estado Democrático de Direito instituído no Brasil tem por objetivo afastar as possibilidades de atuação de governos autoritários, com o direcionamento das ações do Estado na economia de modo a proporcionar uma intervenção indireta através das normas e intermediária através das agências de regulação. 


\section{A SEPARAÇÃO DE PODERES E O PADRÃO DEMOCRÁTICO}

O estabelecimento do Estado liberal burguês, a partir do questionamento referente ao poder absoluto, concentrado nas mãos do monarca, determinou o surgimento de um novo modelo político decorrente da busca por liberdade pela sociedade e da necessidade de limitação do poder atribuído aos representantes do povo.

Para tanto, passou-se a utilizar um conceito já tratado desde a Grécia antiga, mais especificamente por Platão. Trata-se da separação de poderes do Estado, que teve fundamentação relevante a partir dos conceitos de Aristóteles, que dividia a Cidade em poder de deliberação sobre assuntos políticos, magistraturas e poder judiciário. A partir dessa concepção, várias outras surgiram com intuito de aperfeiçoar o conceito, chegando às definições de John Locke, que apontava para uma divisão quadripartida dos poderes do Estado, entre Legislativo, Executivo, Federativo e Prerrogativo. Em seguida, foram concebidas as principais definições sobre o tema da separação de poderes, qual seja, aquela elaborada por Montesquieu. (BRITO; DOMINGUES, 2014, p. 4)

Segundo Montesquieu, a divisão tripartida dos poderes do Estado deveria ocorrer com o estabelecimento do Poder Legislativo, Poder Executivo e Poder Judiciário, sendo que cada um desses poderes deveria ser limitado por outro, de modo a controlar as atribuições conferidas ao representante da sociedade, dividindo-os de forma equilibrada, com limites recíprocos.

\footnotetext{
Quando, na mesma pessoa ou no mesmo corpo de magistratura, o poder legislativo está reunido ao poder executivo, não existe liberdade; porque se pode temer que o mesmo monarca ou o mesmo senado crie leis tirânicas para executá-las tiranicamente. Tampouco existe liberdade se o poder de julgar não for separado do poder legislativo e do executivo. Se estivesse unido ao poder legislativo, o poder sobre a vida e a liberdade dos cidadãos seria arbitrário, pois o juiz seria legislador. Se estivesse unido ao poder executivo, o juiz poderia ter a força de um opressor. Tudo estaria perdido se o mesmo homem, ou o mesmo corpo dos principais ou dos nobres, ou do povo exercesse os três poderes: o de fazer as leis, o de executar as resoluções públicas e o de julgar os crimes ou as querelas entre os particulares. (MONTESQUIEU, 2005, p. 168).
}

A separação de poderes evidencia, ainda, a necessidade de atribuição às estruturas orgânicas de suas funções que sejam independentes entre si, bem como sejam compostas de especialização para o exercício e possuam determinadas prerrogativas.

Por meio dessa separação dos poderes, entre executivo, legislativo e judiciário perante o contexto do Estado Democrático de Direito, objetivou-se concretizar um governo baseado no 
equilíbrio entre as forças políticas mediante controles recíprocos proporcionados pelo sistema de freios e contrapesos, a fim de efetivar os direitos fundamentais.

\begin{abstract}
De acordo com Montesquieu, o "poder de julgar" deveria ser exercido por meio de uma atividade puramente intelectual, não produtiva de "direitos novos". Essa atividade não seria limitada apenas pela legislação, mas também pela atividade executiva, que teria também o poder de executar materialmente as decisões que constituem o "poder de julgar". Nesse sentido, o poder dos juízes ficaria limitado a afirmar o que já havia sido dito pelo Legislativo, devendo o julgamento ser apenas "um texto exato da lei". Por isso, Montesquieu acabou concluindo que o "poder de julgar" era, de qualquer modo, um "poder nulo" (en quelque façon, nulle). Assim, conferiu-se o poder de criar o direito apenas ao Legislativo. A prestação judicial deveria se restringir à mera declaração da lei, deixando-se ao executivo a tarefa de executar as decisões judiciais. Para que se pudesse limitar o poder do juiz à declaração da lei, a legislação deveria ser clara e capaz de dar regulação a todas as situações conflitivas. Os Códigos deveriam ser claros, coerentes e completos. O medo do arbítrio judicial, derivado da experiência do ancien régime, não apenas exigia a separação entre o poder de criar o direito e o poder de julgar, como também orientava a arquitetura legislativa desejada. Além disto, o racionalismo exacerbado, típico da época, fazia acreditar que a tarefa judicial poderia ser a de apenas identificar a norma aplicável para a solução do litígio. (MARINONI, 2009, p. 29)
\end{abstract}

Nesse sentido, o que pretendia Montesquieu era a atribuição de uma posição neutra à função jurisdicional, em sentido oposto ao que se verificava anteriormente, em que ocorria uma até mesmo uma certa confusão entre essa função e a administrativa.

O sistema instituído no Estado possui como padrão de funcionamento a existência de duas esferas que se completam, quais sejam, a sociedade civil e o governo. A relação entabulada entre elas, saliente-se, com contribuição de ambos, é que cria o espaço político e social, de modo que a concepção política a ser estabelecida deve reconhecer essa troca para possibilitar a adequação à estrutura social. (KURTZ, ROVER, 2015, p. 191)

Durante o Estado Autoritário, os governantes não se viam vinculados à observância de certos requisitos para realizar os atos administrativos. Isso ocorria ao bel prazer daquele a quem interessava, agindo de modo a se beneficiar, bem como aos seus pares, sem qualquer preocupação com o verdadeiro objetivo da função por ele exercida em favor da sociedade.

Essa característica decorre do patrimonialismo, onde não havia grande distinção entre o público e o privado. Os governantes faziam total confusão entre esses conceitos. Consideravam o Estado como seu patrimônio. Com o passar do tempo novas sistematizações foram surgindo, aproximando cada vez mais as normas concernentes ao tema, da realidade e das necessidades demonstradas. 
O Estado Democrático trouxe consigo uma carga burocrática. O resultado foi o surgimento de procedimentos com a finalidade de garantir a observância dos princípios constitucionais. No ordenamento jurídico brasileiro, os princípios burocráticos foram contemplados, de fato, com o advento da Constituição da República Federativa do Brasil de 1988. (MEIRELLES, 2009. p. 249)

O início da burocracia fez com que o patrimonialismo perdesse força. Os ideais democráticos passaram a assegurar a observância dos princípios consagrados pela Constituição.

A atual Constituição da República Federativa do Brasil, promulgada em 1988, veio a consolidar os valores democráticos que floresciam após o fim da ditadura militar, rompendo, pois, com a ordem política vigente no referido Estado autocrático de exceção e trazendo consigo a positivação dos anseios sociais do povo brasileiro. Esses ideais foram incorporados no ordenamento jurídico brasileiro com o intuito de afastar as práticas contrárias ao desenvolvimento da nação e, consequentemente, ao benefício de toda a população.

Consequência da instituição do Estado Democrático de Direito é o contido no artigo $1^{\circ}$ da Carta Cidadã, que define: “Art. $1^{\circ}$ A República Federativa do Brasil, formada pela união indissolúvel dos Estados e Municípios e do Distrito Federal, constitui-se em Estado Democrático de Direito e tem como fundamentos (...)". Ainda, vai além e define, no parágrafo único do referido artigo, que o povo é o titular do poder: "Todo o poder emana do povo, que o exerce por meio de representantes eleitos ou diretamente, nos termos desta Constituição."

O conceito de Estado Democrático de Direito decorre da evolução do Estado de Direito, surgido a partir do Estado Liberal. Considerando a insuficiência do conceito inicial proposto pelo Estado de Direito, surgiu, então, a figura do Estado Social de Direito, tendo por postulado a inserção da democracia enquanto realização dos valores, hoje consagrados na Constituição, de liberdade, igualdade e dignidade da pessoa. (SILVA, 2007, p. 114)

Nesse passo, o Direito como um todo é dotado de normas que devem ser interpretadas à luz dos princípios constitucionais, a fim de que a sociedade em geral seja beneficiada por posicionamentos uníssonos e coerência para a solução de litígios.

Tal fato se dá em decorrência da difusão da aplicação dos princípios, direitos e garantias constitucionais a todos os ramos do Direito, demonstrando unidade ao ordenamento jurídico.

Segundo as sábias lições de Miguel REALE: 
(...) o adjetivo "Democrático" pode também indicar o propósito de passar-se de um Estado de Direito, meramente formal, a um Estado de Direito e de Justiça Social, isto é, instaurado concretamente com base nos valores fundantes da comunidade. "Estado Democrático de Direito" nessa linha de pensamento, equivaleria, em última análise, a "Estado de Direito e de Justiça Social". A meu ver, esse é o espírito da Constituição de 1988 (...) (REALE, 1998. p. 2)

Segundo tal posicionamento, o significado de Justiça Social está baseado em perseguir um equilíbrio entre o poder econômico e a defesa social, com intuito de promover a participação dos cidadãos no desenvolvimento na nação. Ainda, pelo entendimento de Jonh Rawls, a Justiça Social não é apenas o equilíbrio buscado por Reale, mas também, entre outras coisas, a garantia das liberdades fundamentais para todos. (SILVEIRA, 2014, p. 12)

Ressalta-se que esta posição deve ser considerada como um dos pilares da noção de Estado, visto que impõe limites à atuação do Estado com base na lei (MELLO, 2005, p. 83), de modo que seu desempenho deve ser regido pela lei maior de nosso ordenamento jurídico, qual seja, a Constituição da República Federativa do Brasil, fazendo prevalecer o princípio da legalidade na atuação dos Poderes do Estado, que "é certamente a diretriz básica da conduta dos seus agentes. Significa dizer que toda e qualquer atividade administrativa deve ser autorizada por lei. Não sendo, a atividade é ilícita.” (CARVALHO FILHO, 2011, p. 13)

\section{A REALIDADE BRASILEIRA E AS DISTORÇÕES DO SISTEMA}

O modelo liberal implementado no Brasil não se iguala ao que lecionavam os teóricos contratualistas nos séculos XVIII e XIX. A legislação vigente intermedia os anseios do Estado liberal e os direitos fundamentais, individuais e as liberdades dos cidadãos, seus direitos de primeira e segunda geração.

Assim, o Estado presta serviços de auxílio aos que mais necessitam da sua intervenção, por exemplo a classe trabalhadora. Dentre os benefícios que o Estado objetiva prover estão inseridas a saúde, moradia e previdência. Ocorre que, infelizmente, a conta ao governo não fecha.

A ideia de serviço público universal não cabe no sistema capitalista mais rígido, como o europeu, diferente do que ocorre no Brasil, em que se prevê na Constituição a universalização dos serviços públicos, possibilitando o acesso até mesmo àqueles que possuem condições de pagamento.

Esse conceito adotado no Brasil nasceu na Alemanha, no contexto histórico do pós segunda guerra mundial, em que os serviços públicos precisavam ser democratizados, visto que 
era uma demanda latente da população naquele momento. Estava consignado na Constituição de Weimar, assim nasceu a social democracia. Apesar de não possuir o mesmo histórico que a Alemanha, no Brasil adota o mesmo conceito dessa chamada social democracia.

No Brasil, a maior parte dos serviços públicos são sustentados pela classe que mantem o proletariado. Ou seja, a maioria dos impostos são pagos pela indústria, serviços e comércio. As empresas da Administração Pública submetem-se ao mesmo regime das empresas particulares, pois não podem ter qualquer vantagem que não seja proporcionada também aos particulares, conforme previsto no artigo 173 da Constituição Federal. A geração de riqueza está na sociedade civil, em decorrência da exigência capitalista.

Ocorre que, diferente do que a realidade fática demanda, o Estado se depara com a autorreferência da estrutura administrativa, que significa que o Estado arrecada apenas o suficiente para manter o equilíbrio das contas públicas. $\mathrm{O}$ custo da prestação, com o custo do serviço, é mantido pela produção econômica da indústria, serviços e comércio, limitando-se a arrecadar apenas o que efetivamente é previsto como necessário.

Porém, pelo modelo capitalista, um Estado não pode ficar estagnado. Não é possível que o Estado arrecade apenas ou até menos do que gasta, pois isso causa o colapso da social democracia. O aumento dos custos para a manutenção da estrutura e, consequentemente, a redução dos valores disponíveis para a sociedade civil, impossibilita o financiamento da classe proletária.

A atividade do Estado é sempre deficitária, bem como o aumento da estrutura administrativa e dos custos para a manutenção é evidente. Atualmente, o capitalismo trabalha com a diferença de grau de confiança e de rentabilidade entre os países. Quando a estrutura administrativa começa a custar demais, ela não fomenta mais a produção econômica. Isso, pois, o aumento de despesas faz com que a quantidade de empregos seja reduzida para diminuir as despesas, gerando, consequentemente, o aumento do número de necessitados da assistência governamental.

Por essa razão, o modelo de Estado Social possui prazo certo, pois se exaure, não havendo como sustentar uma estrutura administrativa que custa mais do que oferece, em que o dinheiro não se reverte em fomento ao modelo econômico, para aumentar empregos e gerar riquezas. Ou seja, a insistência no estado social coloca em risco o próprio sistema democrático.

Não apenas nesse aspecto é que o modelo atualmente vigente no país se mostra deficiente, mas também na sua forma de representação resta evidente a necessidade de 
despender maior atenção, visto que, na prática, ocorrem diversas distorções em relação aos verdadeiros objetivos da democracia e do modelo de separação de poderes.

O sistema de governo conforme atualmente adotado no Brasil, o presidencialismo, pressupõe uma forma de governo pautada na escolha democrática, pelo povo, daqueles que serão seus representantes, em todos os âmbitos da federação.

Partindo dessa premissa, faz-se necessário, periodicamente, a organização de eleições para selecionar os candidatos que passarão a exercer as funções públicas, em forma de representação de toda a população.

A principal função das eleições é possibilitar ao povo a participação no processo decisório, o exercício da soberania popular, inscrito no artigo $1^{\circ}$, parágrafo único, da Constituição da República Federativa do Brasil:

\footnotetext{
Eleições competitivas podem ser consideradas como um dos alicerces dos regimes democráticos contemporâneos, pois representam uma das únicas formas de participação do povo no processo decisório. Pode-se muito bem afirmar que, pela ótica da democracia liberal, onde não há eleições competitivas, não há democracia. (SILVA, 1999, p. 37)
}

Nesse passo, uma vez escolhido o representante para o cargo, ele se torna o titular absoluto por seu mandato, responsável por nomear aqueles encarregados de auxiliá-lo, como os ministros ou secretários, inexistindo necessidade de prévio controle para tanto e à revelia da vontade direta da população, visto que os direitos políticos dos cidadãos estão adstritos ao voto periódico para escolha de seus representantes. (MARTINS, 2010, p. 151)

Ocorre que, infelizmente, o sufrágio conferido aos cidadãos possibilita a ocorrência de distorções em relação aos objetivos esculpidos no Estado Democrático de Direito, tendo em vista que, muitas vezes, artifícios indesejados são aplicados para que benefícios obscuros sejam alcançados, às margens da legislação vigente.

A história demonstra que, desde os primórdios do processo eleitoral no Brasil, a vontade popular, apresentada através do voto, possui relativa contaminação em face do dinheiro que falseia a representação. Os candidatos passaram a ser transformados em produtos e vendidos aos eleitores, de modo que o político "sem máscaras", dotado de boas ideias e compromissos, mas sem contribuição substancial das técnicas de marketing, dificilmente tem êxito na campanha e acaba por ser eleito pela vontade popular apresentada nas urnas. (DIAS, 2004, p. 20) 
Na prática é possível verificar que as doações do setor privado privilegiam diretamente políticos ligados às grandes empresas e corporações, comprometendo a equidade entre os candidatos, pois recebem verbas milionárias para campanhas de forma a macular o resultado pelo poder econômico exercido. Isso faz com que aqueles candidatos beneficiados por volumosas contribuições financeiras se perpetuem no poder. Consequência de tal situação é que os candidatos acabam por se tornar escravos dos desejos de seus patrocinadores. (CAMARGO, 2013, p. 8)

Essas práticas existentes no financiamento de campanhas eleitorais pela iniciativa privada têm resultado num ciclo de ilegalidades, pois são realizadas doações de forma indevida para custear a campanha de determinado candidato. Após ser eleito, esse candidato precisa demonstrar gratidão e retribuir as colaborações com algumas vantagens aos particulares que colaboraram anteriormente, seja com licenciamentos, isenções de taxas em investimentos realizados, licitações ou outros.

A grande disparidade das riquezas existentes no Brasil possibilita aos detentores de grandes fortunas realizarem contribuições maiores que todos os demais doadores com menor poder econômico. Nesse passo, a corrupção política pode ser favorecida, pois grandes empresários poderão doar para campanhas no intuito de obter benefícios futuros, como a celebração de contratos com o Poder Público. (REIS, 2012, p. 456)

Entretanto, não se está, aqui, a fomentar o financiamento exclusivamente público de campanhas eleitorais, principalmente pelo fato de que não há disponibilidade imediata de recursos públicos para custear as campanhas tanto em âmbito federal, como estadual e municipal. Restaria necessário, para possibilitar a efetivação desse sistema, implementar um projeto para arrecadar fundos suficientes para esse financiamento.

Ou seja, para instituir o financiamento exclusivamente público das campanhas eleitorais, caberia ao Estado alterar seu plano de despesas, deixando de investir em alguma demanda social para aplicar verbas no custeio das despesas das campanhas eleitorais, ou arrecadar valores para destinação exclusiva aos partidos políticos, mediante criação de novos impostos ou aumento dos já existentes.

Nesse passo, a adoção de um sistema eleitoral pautado no financiamento exclusivamente público das campanhas eleitorais ensejaria um aumento considerável nas despesas ordinárias que devem ser arcadas por parte do Estado, ocasionando, por consequência, 
um colapso no plano orçamentário e a impossibilidade de investimento em algumas demandas de extrema relevância para a população.

Não apenas os investimentos nas campanhas eleitorais, realizadas por detentores de elevado potencial econômico acabam por desviar a finalidade da democracia. Há, também, a utilização indevida da máquina pública em favor de um indivíduo, normalmente um candidato à reeleição, sua ou de algum sucessor.

Nessas hipóteses, pode o detentor do poder, ou aquele que almeja tal situação, utilizar os cargos a que disporá para nomeação de seus aliados políticos, em troca de apoio durante o período eleitoral, angariando votos, e também no curso do mandato. Aos servidores efetivos, muito ocorre a utilização da máquina pública para conseguir apoio político pelo candidato através da concessão de benefício incorporados aos vencimentos, por exemplo as gratificações, que em muitas oportunidades são proporcionadas sem qualquer critério efetivamente válido à Administração Pública.

Nesse aspecto, os verdadeiros objetivos da democracia acabam desvirtuados, seja pela perpetuação no poder através da utilização indevida da máquina pública, seja pelo capital investido nas campanhas eleitorais para a "aquisição" de votos em troca de benefícios perante a Administração Pública aos particulares que contribuíram para essa situação.

Em qualquer dessas hipóteses, o resultado prático é o mesmo, a má utilização dos recursos públicos, uma administração ineficiente, de modo que o atendimento às demandas da população, para a efetivação da social democracia que se pretende no país, que já era extremamente difícil, torna-se impossível. Assim, ou se supera o modelo estatal, ou chegará à falência do Estado, ao seu exaurimento. 


\section{CONSIDERAÇÕES FINAIS}

Pelo presente estudo se objetivou despertar o raciocínio acerca da realidade proporcionada pelo Estado Democrático de Direito estabelecido no Brasil, a partir da utilização de conceitos provenientes tanto do modelo econômico liberal, quanto do modelo econômico social.

O constitucionalismo, enquanto acordo entre sujeitos, impõe uma relação de direitos e deveres, criando uma relação jurídica obrigacional entre o Estado e os cidadãos. Por atender a um modelo de social democracia, além da previsão de ilicitude quando da ocorrência de abusos por parte do Poder Público, o Estado também gera ato ilícito quando se omite à prática de ato que lhe era atribuído, sem que haja a devida justificativa.

A social democracia estabelecida no Brasil não possui condições de vigorar por muito tempo, visto que está encaminhando o Estado para um colapso por não ter condições de proporcionar tudo aquilo a que se propõe, nos termos consagrados pela Constituição da República Federativa do Brasil, de 1988.

O Estado tem sido utilizado para socorrer a crise do modelo capitalista prestando serviços de assistência aos trabalhadores. A prestação de serviços públicos é inserida no ordenamento, passando a reconhecer aos indivíduos, além dos direitos fundamentais, os direitos sociais, também chamados de direitos de segunda geração.

Por fim, o padrão democrático adotado enfrenta uma série de distorções. Os representantes do povo, eleitos pelo voto popular, acabam por ser definidos não pela vontade real da população, mas por interesses escusos, vinculados a benefícios particulares.

Sendo o Estado obrigado a proporcionar à população o auxílio necessário, em decorrência do princípio social, faz-se necessária a arrecadação de valores, por ele, em montante superior ao que se estabelece atualmente, que não é suficiente nem mesmo para suprir as despesas existentes. Nesse passo, não havendo recursos suficientes para a execução de todos os planos que lhe são imputados, o Estado, por meio de seu gestor, precisa definir as prioridades para os investimentos a serem realizados.

Em face de tal situação, o que tem ocorrido na prática é que os recursos que já são escassos acabam, por má gestão, sendo disponibilizados em proporções ainda menores. Além disso, a disponibilidade dos recursos ao gestor possibilita a destinação conforme seu interesse particular, beneficiando apenas alguns em detrimento da coletividade, valendo-se indevidamente da máquina pública para benefícios próprios. 
Portanto, o que se evidencia é que não apenas o modelo econômico adotado se encontra em vias de se exaurir, mas também a própria democracia não consegue se legitimar em face do seu desvirtuamento, perante as distorções proporcionadas no sistema do Estado Democrático de Direito. 


\section{REFERÊNCIAS}

BERCOVICI, Gilberto. As origens do Direito Econômico: homenagem a Washington Peluso Albino de Souza. Revista da Faculdade de Direito da UFMG, Número especial em homenagem a Washington Peluso Albino de Souza. 2013.

BRITO, Deborah Cristiane Domingues de; DOMINGUES, Wilson Francisco. Separação de poderes e tensões constitucionais: garantia de direitos fundamentais pelo Poder Judiciário. Disponível em: < http://publicadireito.com.br/artigos/?cod=cb032fff92d5d7fd $>$. Acesso em: 11 abr 2016.

CAMARGO, Guilherme Pessoa Franco de. O financiamento público exclusivo de campanha - uma chance de liberdade. Disponível em: <http://www.tre-sc.gov.br/site/resenha-eleitoral/n3-janjun-2013/integra/artigos/o-financiamento-publico-exclusivo-de-campanha-uma-chancede-liberdade/index 83d7.html?no_cache=1\&cHash=9d3218b6e926210db78af3d2d6b8d3f9>. Acesso em: 07 abr 2016.

CARVALHO FILHO, José dos Santos. Manual de direito administrativo. 24. ed. Rio de Janeiro: Lumen Juris, 2011. p. 13.

DIAS, Mauricio. A mentira das urnas: Crônicas sobre dinheiro e fraudes nas eleições. Rio de Janeiro: Record, 2004. p. 20.

KOURY, Suzy Elizabeth Cavalcante. A CRFB/88, o capitalismo e a intervenção do estado no domínio econômico: a busca pelo desenvolvimento econômico, social e humano. Disponível em: <http://publicadireito.com.br/artigos/?cod=2bec3f7f8208e144>. Acesso em: 04 abr 2016.

MARTINS, Ives Gandra da Silva. Parlamentarismo e Presidencialismo. In: COÊLHO, Marcus Vinícius Furtado; AGRA, Walber de Moura. Direito eleitoral e democracia: Desafios e perspectivas. Brasília: OAB, 2010. p. 151.

MEIRELLES, Hely Lopes. Direito administrativo brasileiro. 35. ed. São Paulo: Malheiros, 2009. p. 249.

MELlO, Celso Antônio Bandeira de. Curso de Direito Administrativo. 18. ed. São Paulo: Malheiros, 2005. p. 83.

MONCADA, Luis S. Cabral de. Direito econômico. 4. ed. Coimbra: Centelho, 1978.

MONTESQUIEU. O Espírito das Leis. Tradução Jean Melville. São Paulo: Martin Claret, 2006.

RAMOS, Emerson Erivan de Araújo. Cidadania moderna e liberalismo clássico: uma perspectiva histórico-filosófica. Disponível em: <http://www.conpedi.org.br/publicacoes/c178h0tg/j3hjp1xw/we4Ds5bYoV6i4TdN.pdf>. Acesso em: 05 abr 2016.

REALE, Miguel. O estado democrático de direito e o conflito das ideologias. São Paulo: Saraiva. 1998. p. 2. 
REIS, Márlon. Direito Eleitoral Brasileiro. Brasília: Alumnus, 2012. p. 456.

ROSSIGNOLI, Marisa; FERRER, Walkiria MartinezHeirich. Estado liberal ou intervencionista? Uma análise econômica do atual modelo do Estado brasileiro. Disponível em: < http://www.publicadireito.com.br/artigos/?cod=e9352a4485132942>. Acesso em: 09 abr 2016.

SILVA, Luís Virgílio Afonso da, Sistemas eleitorais. São Paulo: Malheiros, 1999. p. 37.

SILVA, José Afonso da. Curso de Direito Constitucional Positivo. 22. ed. São Paulo: Malheiros, 2003.

SILVEIRA, Denis Coitinho. Teoria da justiça de John Rawls: entre o liberalismo e o comunitarismo. Disponível em: <http://www.scielo.br/pdf/trans/v30n1/v30n1a11.pdf >. Acesso em: 21 ago. 2014.

VILELA, Francy José Ferreira. O Liberalismo Político de John Locke. Disponível em: $<$ http://revistapandorabrasil.com/revista_pandora/politica_60/francy.pdf $>$. Acesso em: 08 abr 2016. 